\title{
Improving Health Literacy through Governance Tools
}

\author{
Sedat Kula, Ph.D. (Corresponding author) \\ Training Department of Turkish National Police \\ Ankara, Turkey 06510 \\ Email: sedatkula@yahoo.com \\ Beth Ann Fiedler, Ph.D. CEO Data2Policy \\ 1515 Alexandria P1 N, Jacksonville, FL USA \\ Email: data2policy@gmail.com
}

Accepted: February 25, 2014

doi:10.5296/jpag.v4i1.5282 URL: http://dx.doi.org/10.5296/jpag.v4i1.5282

\begin{abstract}
Health literacy involves more than the absence of reading skill. Additional dimensions include the comprehension and interpretation of information in order to make informed health decisions. We suggest that health care service providers must engage their patient population to improve their level of personal responsibility through the systematic process of selection, implementation, and critical evaluation of acknowledged tools of governance. To successfully increase health literacy in this complex and dynamic environment, this solution proposes an intensive strategy through the collective use of governance tools across multiple participants that include the health care sector, political representation, regulatory representatives, health insurance providers, Non-Government Organizations, patients, and the education system. We offer a detailed example of governance methods applied to healthcare and summarize these recommendations in a program logic model that provides a roadmap of planned events leading to problem resolution over time. The U.S. National Action Plan to Improve Health Literacy using a multi-sectoral approach has been a model for other nations.
\end{abstract}

Keywords: Health Literacy, Governance Tool, Multi-sectoral Approach 


\section{Introduction}

Health literacy is a growing concern in the pharmaceutical industry as estimates indicate about 90 million Americans do not have sufficient skills to understand and complete instructions on medications and support materials presented in written, oral, or digital format (National Patient Safety Foundation, 2007; Nielsen-Bohlman, Panzer, and Kindig, 2004; Andrus and Roth, 2002). Personal struggles are complicated by disparate label standards and communication difficulties that contribute to reduced health outcomes that increase mortality and morbidity. Finally, the cost burden of low health literacy to the American public accounts for two-thirds of expenditure (Parker, Ratzan, and Lurie, 2002). Therefore, improving low health literacy can save the US health care system preventable costs ranging from $\$ 106$ to \$236 billion depending on the patient population (National Patient Safety Foundation, 2007).

Three tools of governance were selected to help determine their cumulative impact on the growing issue of health literacy. They include collaboration and partnership, regulation, and direct government. This paper will provide background and problem scope in order to generate detailed actionable examples using the tools of governance to encourage multi-level participation that leads to improved health literacy.

\section{Historical Background}

Health literacy embraces a broader concept comprised of cultural differences in terms of understanding health care; writing, speaking, and listening skills; and the degree of familiarity with health related terminology and concepts (Weiss, 2007; Partnerships for Clear Communication, 2006; Shoet, 2002). Two additional dimensions of the term include the Joint Commission (2007) position that the detailed format of delivery used by medical professionals also contributes to the problem complexity. Thus, the development of mechanisms that increase the two-way communication between physician and patient are increasingly relevant.

Health decisions are based on knowledge gained about health and health care that leads to increased ability in several areas. They include the ability to seek, understand, and interpret health information that leads to appropriate medical care formulated through a critical decision-making process about health status (Rootman and Ronson, 2005).

The Institute of Medicine (2001) indicates that this health literacy process consists of educational, social, and cultural factors that shape the people's expectations from health care providers (Weiss, 2007; Partnership for Clear Health Communication, 2006). Subsequently, these same factors act on service providers' capability to meet those expectations. Kickbusch, Maag and Saan (2005) formally defines health literacy in a more comprehensive way: "Health literacy is the ability to make sound health decisions in the context of everyday life-at home, in the community, at the workplace, the health care system, the market place, and the political arena."

This complete definition properly expands the impact of the issue in agreement with notable research on the matter such as the Ad Hoc Committee on Health Literacy (AHCHL) 1999 report that was supported by the Council on Scientific Affairs of the American Medical 
Association. After reviewing two-hundred and sixteen published articles between 1966 and 1998, the committee unveiled conclusions that link poor health literacy to adverse health outcomes.

Due to a complex array of common difficulties reported to the AHCHL this patient population experiences "worse health status and have less understanding about their medical conditions and treatment" (Kickbursh et al., 2005). Consequently, they increase their risk of hospitalization due to delays in preventative medicine that prevent proper treatment regimens to begin and continue as needed. Results of the AHCHL (1999) also concluded that health literacy is a stronger predictor of health status compared to age, educational level, income, employment status, and race (Weiss,2007). Further, findings from the Coulter, Entwistle and Gilbert (1999) study linked health literacy directly to the delivery of appropriate health information. The cumulative findings provide substantial direction for the formulation of multi-level, collaborative medical interventions in order to increase health outcomes through health literacy improvements.

\section{Problem Significance}

The significance of low health literacy is two-fold in nature. First, the added financial burden on an already strained health care system and second, the direct impact on morbidity and mortality. The impact across multiple populations is increasingly evident as estimations from those who receive public health services, pharmaceutical users, and chronic patients are reviewed.

The medical community recognizes that low health literacy characterized by a reading level at or below sixth grade (Davis, Wolf and Bass, 2006; Shoet, 2004; Shoet, 2002) results in significant health disparities such as the overuse and underuse of medications that increase the risk of premature death (Tracz, Metzger and Pruchnkicki, 2008). In addition, the National Academy on an Aging Society (NAAS) (Parker et al., 2003) conducted a preliminary analysis of the costs of low health literacy to the American public and estimated a range of \$48-119 billion annually as measured by relative share of Gross Domestic Product (defined as the value in the current market in 2008 U.S. dollars). Parker et al. (2003) reported that nearly two-thirds of the health care burden is attributed to low health literacy that translates into increased public health care costs and added tax burdens on the general population.

Patient medical consequences related to low health literacy are more likely to have poor health status, longer hospital visits, and more medical treatment errors due to difficulties resulting from poor communication. They are also less likely to use preventive services, which results in higher health care costs to the system. The decreased use of preventative services also contributes to higher rates of hospitalization (Schwartzberg, VanGeest and Wang, 2005; Sihots and Lennard, 2004). The resulting impact of higher public health service in the US - an underlying health literacy factor that influences health outcomes, costs an estimated $\$ 120$ billion annually in 2008 US Dollars (Parker et al., 2003). More than 90 million Americans who suffer from low literacy in the US are also elderly and/or low income (Nielson-Bohman, Panzer, and Kindig, 2008; Nielsen-Bohman et al., 2004). 
Low health literacy patients with chronic health conditions require long-term health care and must adhere to more rigid prescriptions. This patient population with advancing diseases that require increasingly complex treatment and prescription regimens is expected to worsen conditions based on the increased costs of associated medical needs due to potential lack of adherence (Fiedler and Wan, 2010; Evert et al., 2004).

Parker cites the $\$ 510$ billion price tag in 2000 (\$740 billion in 2008 US Dollars) accumulated by approximately half of the American public that suffers from some form of chronic condition (e.g., diabetes, heart conditions). The future projection from the initial estimates expects that these costs will grow to over $\$ 1$ trillion dollars by $2020,63 \%$ of which can be eliminated by increasing health literacy (Parker et al., 2003).

\section{Governance Tool Evaluation Criteria}

Five major public action tool evaluation elements are identified by Salamon. They are feasibility, equity, effectiveness, efficiency, and manageability (Salamon, 2002).

Evaluation elements that validate policy tool selection initially rest on the political, economic and technical feasibility of the proposed intervention(s) based on legitimacy derived from achieving political neutrality. Political neutrality is achieved when support is obtained from elected officials and politicians. Lack of political support can cause a significant barrier to policy implementation and therefore requires inclusion of powerful stakeholders that could otherwise place obstacles to effective implementation. (Salamon, 2002).

Economic feasibility takes precedence in the rational decision-making process because government sponsored service requires a cross-subsidization method that will consider both pricing and level of service that normally span diverse populations. As a result, the concept of Distributive Justice (Rawls, 1971) is often invoked since services to populations with a higher socioeconomic status (SES) will incur greater service costs than those with a lower SES so that the least advantaged members can benefit from public action.

The focus on the cost and level of service of public action also supports a third policy evaluation tool-equity. Inherent in the equity evaluation are the basic concepts of fairness and the redistribution of goods and/or services which provide program benefits to disadvantaged populations in order to remedy social inequality (Salamon, 2002).

Delivery of goods and services in an equitable fashion is often determined by measuring effectiveness and efficiency. Effectiveness is a fundamental element of evaluation and provides a method to determine if a public action has been successful in reaching their specific objectives. The introduction of efficiency measures that balance results against costs can help to predetermine what public action or combination of public actions can provide optimum solutions at the least transaction cost. Efficient use of limited resources requires the optimum balance between benefits and cost and is critical to the policy process (Salamon, 2002).

Ease of implementation or manageability of a program directive and innovations that result from public action are often overlooked as a key factor in implementation. If policy is 
analyzed across diverse platforms inclusive of the complete cycle of public action, manageability can provide program managers with corrective actions to operational dimensions and facilitate new methodology or policy process innovations from the combined perspective. Therefore, both manageability and innovation may be increased with proper coordination of multiple actors (Salamon, 2002).

The level of coerciveness, directness, automaticity, and visibility of direct government (Salamon, 2002) are pivotal evaluation tool attributes. For example, measurement outcome problems with manageability may be attributed to automaticity in which program management did not optimize existing structures and subsequently could not adequately control for program dynamics due to structural differences. In turn, these may lead to a lack of resource visibility and accountability. Further, if delivery of goods and services were executed by multiple representatives, the scenario would further deteriorate which could lead to a level of coercion that fails to elicit outcomes in expected behavioral changes. However, the five public action tools selected in this study incorporate the recognized features of direct government that lead to a higher policy rate of success.

\section{Improving Health Literacy by Governance Tools}

Three governance tools were selected to make contributions to the improvement of health literacy. They are collaboration and partnership, social regulation, and direct government.

\subsection{Collaboration and Partnership}

The multi-dimensional nature of health literacy cannot be resolved with a one-dimensional approach where the burden of resolution is placed solely on the health care service provider. Instead, the evolution of governance tools, such as the formation of partnerships representative of different sectors and other less formal forms of collaboration, provides an alternative problem-solving mechanism to the historically rigid, hierarchical government approach.

Cooperative information systems facilitate information sharing and access to data that constitute the benefits of interagency cooperation and networking leading to efficient, effective, and integrated program responses. Easy access to information, which is a direct result of information sharing, increases the agent ability to respond to problems more effectively and in a timely manner (Landsbergen and Wolken, 1998). Multi-disciplinary collaborations and partnerships also have the added benefit of standardizing complex medical jargon that help to eliminate misunderstanding.

Because we live in an increasingly networked world, we need a variety of alternative forms of organizations that differ from traditional bureaucracies. Rapid changes in technology, scarce resources, and organizational interdependence emerge these new forms through collaboration resulting in interactions that lead to the establishment of new social structures (Thomson, Perry and Miller, 2009; Moynihan, 2005). Regardless of organization structure - private, public, profit, and non-profit, there has been an increased demand for organizations to demonstrate networked collaborative relationships to achieve complex policy goals. In this context, collaboration is seen as a way to efficiently allocate scarce 
resources that help build better communities (Thomson et al., 2009; Thomas, 1997). Resolution of interconnected problems requires some government intervention even as we recognize the value of governance to elicit effective and efficient health literacy solutions. Structural government still provides social, economic, and political stability that permit collaborative experimentation and resolution during implementation of public policy.

Collaboration is defined as a process through which parties that view different aspects of a problem can constructively explore their differences and search for and implement solutions that expand their own limited vision of what is possible (Taylor-Powell, Rossing, and Geran, 1998). Interagency cooperation seeks three main purposes: matching needs and providing coordination, limiting duplication of services, and ensuring task accomplishment (Mattessich, Murray-Close and Monsey, 2001).

Governances' aim is simply to accomplish the task based on determining common ground as agreed upon by stakeholders. The horizontal management style of governance creates an atmosphere of mutual responsibility that promotes cooperation towards the common goals through shared knowledge and monetary resources. Since there is no bureaucratic managerial process, improved solutions can be resolved more quickly and efficiently (Goldsmith and Eggers, 2004). Finally, the governance approach fosters citizen participation in the decision-making process. This interaction strengthens democracy by providing an avenue for consumer concern through a public platform where state power is shared with citizens, private parties and non-profit organizations (Newland, 2002).

Within the framework of the governance concept, the first and most important action is building a mechanism to make diverse sectors of health care (e.g., health insurance companies, community-based agencies, multi-level government agencies) effectively work together through collaboration. The use of established community networks can also assist health care professionals in reaching a larger portion of low literate people who found the peer-helper approach to be a more effective method to reach low literate older women compared to traditional educational approaches (Wallerstein and Berstein, 1994). The California Health Literacy Initiative (CHLI), the largest health literacy project in the United States, provides a good example of collaborative efforts on health literacy. This initiative's purpose is clearly defined "to inform and partner with individuals and organizations to craft collective, lasting solutions which will positively impact the health and well-being of individuals with low-literacy skills, their families, and their communities" (Literacyworks, 2008).

In view of this coordinated and integrated approach, this mechanism will provide the ability to review the issue from different perspectives, assess current efforts, and avoid duplication in isolated governmental and non-governmental organizations. Consolidated efforts anticipate more permanent solutions across key partners at the local, provincial, territorial, and international level.

Since Foster-Fishman et al. (2001) reports that inter-organizational alliances such as coalitions and coordination councils facilitate exchange of information among member organizations, a strong link between researchers and policymakers should be established. 
Policy councils or policy commissions can then become the avenue to discuss health issues that lead to efficient and effective solutions that increase social well-being.

An interdisciplinary health literacy policy agenda should be created by the participation of experts from all related agencies resulting in a multi-sectoral health literacy policy council with clearly defined responsibilities and goals. These goals include representation from government, academic, and non-governmental organizations. Members of the private sector, especially from computer and communication industries, can also provide fruitful information about the latest technological developments.

Network type is another important consideration. A fundamental question to initiate this search can be, "How can we achieve ongoing information sharing?" The answer, according to Goldsmith and Eggers (2004), is to create a collaborative knowledge network. There are two dimensions in this kind of network type. First, creation of an electronic gateway which allows organizations to share information throughout the network; second, creation of interactive communities which are comprised of people linked with each other across organizational boundaries. The ongoing interconnectivity of electronic medical records and the continuous promotion of meaningful use make this an opportune time to consider options that further engage technology and timely access to data.

Under the supervision of the policy council, a systematic review of current health literacy policies should lead to measureable improvements. This initial step is considered the most comprehensive policy evaluation method resulting in the determination of optimum programs that conclusively contribute to increased safety and quality of life.

Comprehensive systematic review of all health literacy program evaluations across the United States (including existing tools such as Medicare Beneficiary Survey and National Health Interview Survey), conducted by the established health literacy policy council will provide information about what programs work and what programs do not work. Establishing this information in advance will give policy makers an opportunity to reallocate the funds from unsuccessful programs to those proven more successful (Parker et al., 2003).

\subsection{Social Regulation}

Social regulations and rules identify permissible and impermissible activity for individuals, firms, or government agencies for the purpose of restricting behaviors that directly threaten the public health, welfare and wellbeing. Appropriate sanctions and rewards are two important components of social regulation. Social regulation is generated through internal industry control mechanisms while economic regulation requires judicial and legislative processes that control prices, output, and/or the entry and exit of firms in an industry (Salamon, 2002).

The opportunity to apply social regulation to low health literacy is feasible since the professional medical community has generally acknowledged the need for improved physician-patient communication (Partnership for Clear Health Communication, 2007). The industry goal to use plain and simple health terms is consistent with academic research confirms that health information in a text format is unclear to patients because above average 
reading ability is needed for comprehension (Paasche-Orlow, Taylor and Brancati, 2003).

Kemper and Mettler (2002) emphasize that the health information provided to patients is as important to patient health as surgery and medication. Consequently, they advocate that access to high quality health information should be provided at every point of health care including test results, follow-up care, and medication instructions.

"Teach back" techniques implemented by health care professionals also represent internal mechanisms to help patients understand directions and procedures. In their report titled, "What Did the Doctor Say?:" Improving Health Literacy to Protect Patient Safety", the teach back method is described as "asking the patient to repeat-or teach back-to the treating clinician the important health care information that has been communicated in the health care encounter to assess and ensure the patient's understanding" (The Joint Commission, 2007). In this context, the biggest burden is on health professionals, especially doctors. However, social regulation can be suggested by government and supporting regulatory agencies to promote organization accountability for implementing processes that require their medical staff to use plain language.

The application of social regulation to existing accreditation and liability concerns, which are considered strong motivators for US organizations, may also promote nationally recognized guidelines. Communication standards between patient and health care providers as well as internal processes that evaluate patient understanding and health care service providers, training on appropriate patient response according to their literary level can then be included in the health organizations' accreditation process. For example, the Joint Commission (TJC), a private accrediting agency that inspects all licensed health care facilities and establishes minimum standards for hospitals and other health care institutions, can require all health care organizations to write patient instructions at an understandable level that recognize patient cultural, social, and psychological situations (Shohet, 2002).

Since 2010, the TJC National Patient Safety Goals (NPSG) provides guidance under several categories including Critical Care Hospital, Hospital and Laboratory. A major goal of the NPSG.02-03-.01 is to "Improve the effectiveness of communication among caregivers" that specifically requires these agents of health care to report critical test results to patients in a timely fashion (TJC, 2014). This initiative is a positive move towards increased health literacy as the development of procedures will help define reporting responsibility that promotes accountability. In addition, improved communication is also anticipated from the proper categorization of critical information.

Though individual understanding is urgent, the overall literacy level and language needs of a community also impacts health literacy. Since a majority of people that have low health literacy are elderly and low income, the officials of community-based agencies such as community health centers, homeless centers, and faith-based organizations should be inspired to use social regulation to extend proposed suggestions. This includes extending health literacy training to community agents since they have a large role in escalating service needs and bridging the gap in long-term care. 


\section{Macrothink}

Though easy to read and understandable health information is a useful step towards improving health literacy, plain language is inadequate to address health difficulties and considered supplementary to face to face contact between patient and physician (Perrin, 1998). In this context, Mayeaux et al. (1996) emphasize that a combination of readable materials and simple oral instructions by physicians can enhance patient understanding.

Health care providers (hospitals) should be encouraged to create a vision in which all health care practitioners deal with their patients by using simple and everyday vocabulary. Further, ample time for discussions between practitioners and patients must be properly scheduled. Patients should also be encouraged to have the comfort level to question physicians using open dialog that allows them to feel free to ask what they would like to ask.

The IOM (2001) recognized that the health care system should undergo a reorganization that shifted focus towards patient safety through a 'patient-centered' approach. ${ }^{60}$ The basic premise of this approach is that patients should have a full understanding of all of their viable options (Nielsen-Bohlman et al., 2008). Addressing health literacy through social regulation increasingly appears to be an avenue to promote change.

\subsection{Direct Government}

Citizen education is a main function of the government. Therefore, health literacy education programs should be encouraged by all levels of government.

Even though health education is given as a required course in most elementary, middle, and high schools, there is no consistent coordination of coursework. For instance, while less than half (44 per cent) require health education in grade 5 , health education as a required course for twelfth graders occur in only 2 per cent of schools (Nielsen-Bohlman et al., 2004). The Joint Committee on National Health Standards (JCNHS) published standards that establish essential student skills and knowledge. Although they provide information on what students should know and apply in health education by the end of grades 4, 8, and eleven, the availability of classrooms that teach information to meet the standards is limited (Nielsen-Bohlman et al., 2004). In addition to education goals that focus on improved reading, health literacy and health-related issues requires specific attention beyond basic literacy (Parker et al., 2003). Therefore, general literacy and a specific curriculum that emphasizes the importance of health literacy are needed.

The Department of Education (DOE) can guide related organizations on how to prepare health literacy curriculum for all levels of the education system, beginning from elementary school to college education. The DOE must enforce and manage the continuity of the education process through strict monitoring and accountability for health literacy.

An emphasis on enforcement and strategies that address the continuity of education development, monitoring, and accountability process must also include the medical community. This stance is supported by findings from the JCNHS which indicates that health professionals do not have adequate education, training, or continuing education as far as the health literacy improvement is concerned (Nielsen-Bohlma et al., 2004). In this context, health literacy should become a necessary component of health care professionals' education. 
An increase in professional and public awareness must start with the education of medical students and physicians in order to foster physician-patient communication skills. The JCNHS report suggested that the focus of future research should also generate diagnostic methods through patient screening which aid in the identification of communication deficiencies that lead to low literacy and poor health.

\section{Governance Tools Evaluation}

All selected public policy tools are discussed in detail below as per the section titled "Governance Tool Evaluation Criteria". Evaluation criteria include effectiveness, efficiency, equity, manageability, and feasibility.

\subsection{Effectiveness}

Among the three selected tools targeting the improvement of low health literacy, partnership and collaboration and education are long-term investments in a situation where short-term, positive changes are in demand. Collaboration and partnership is reported as one of the most powerful tools for any interconnected social problems, but time is a factor in order to develop commitment, passion, and trust between the members of all participating organizations for optimum outcomes (Thomson et al., 2009; Provan and Milward, 1995).

Trust between agencies is a significant requirement for interagency cooperation (Lane and Bachman, 1998; Parkhe, 1993) and is defined as the expectation that agencies will mutually exchange information honestly and openly. The effectiveness of collaboration networks are based on the expectation of innovative outputs. For example, if members of a collaborative network "are able to develop new processes that will lead to new ways of working, new structural arrangements and integration of the members into a new whole" (Mandell and Keast, 2007), then the inter-agency commitment will be deemed effective.

Some agencies can anticipate that other agencies will not respond to their partnerships, and that others will take advantage of this assistance. Therefore, trust is, to a large degree, determined by the number of successful exchanges between agencies (Creed and Miles, 1996). However, trust between agencies does not develop easily except over time. Collaboration is generally based on the "I will if you will" mentality until trust is developed between participating organizations. As a result, repeated interactions between partners are needed to build the credible trust and commitment (Thomson et al., 2009).

The establishment of regulations and sanctions to guide hospitals in formulating plain language policies may make the economic regulation tool highly coercive. However, successful collaboration efforts can enforce friendly social regulation within the health care industry. This approach may be less coercive and help to establish common goals even as health care providers undergo changes to their current practices that might be considered highly intrusive. The comparatively small administration costs stemming from social regulation can be significantly less than economic regulation costs from use of the judicial system that must be supported by legislative action. Further, knowledge that others within the network are experiencing the same growing pains through social regulation agreements may help provide accountability and enforcement under more practical terms. 
Active enforcement is a successful method of government also used in governance to achieve desired results. But, collaboration and partnerships can also achieve the necessary enforcement with less financial impact on participants. Therefore, social regulation is the tool in which desired outcomes could be achieved in the short-term while collaboration and partnerships and education work for long-term changes. The capacity to measure improvement in both time frames adds to the ability of policy movers to utilize information to make incremental improvements that can benefit the population and demonstrate effectiveness.

\subsection{Efficiency}

Cost-benefit analysis (CBA) is one of the most widely used analytical methods to evaluate efficiency (Steinemann, Apgar, and Brown, 2005; Dreze and Stern, 1987). CBA enables policy makers to decide the best efficiency course of action and resource allocation among many alternatives that can achieve desired policy outputs.

After evaluating each tool by reviewing their possible benefits and costs, comparison among multiple governance tools in terms of efficiency should be made by using the benefit-cost ratio. Benefit-cost ratio is obtained by dividing total projected benefits to total projected costs associated with each tool. The tool or combination of tool having the highest benefit-cost ratio is considered most efficient.

Training for health care service providers may be costly at the initial stage since instruction on appropriate interactions with patients must be given according to their literacy, cultural, and language levels. However, the additional benefit is considered worth the extra cost since increasing literacy as a result of training increases the usage of preventive services. This, in turn, results in lower health care costs to the system and translates into long-term government savings. As with social regulation, increasing literacy as a result of making written health products simple will decrease potential costs from preventable hospitalization. Ultimately, systemic health care costs can be reduced.

The US government has established various partnerships to help reduce waste. One such agency is the Office of the National Coordinator (ONC) that was established to manage health Information Technology policy initiatives through funding from the American Recovery and Reinvestment Act. The projected outcome of the ONC is the establishment of an information-sharing system and database between related organizations. Coordinating and managing the network will initially increase costs. But, the benefit side of this tool in action would decrease wasteful duplication efforts and increase use of knowledge made available from different fields.

\subsection{Equity}

In order to create enhanced communication between health care practitioners and patients, hospital and other health care administrators must be urged to support structure and policies that enhance literacy across all service providers, without exception. Otherwise, the exclusion of any health care provider or hospital will bring the equality question to the table. This inequality might create tension between hospitals regardless of whether or not they are 
involved in the process. To achieve equity, the proposed health literacy policy council should be created with representation of all related agencies in order to reach harmonious results. In turn, representatives can ensure that information is delivered and accessible to all organizations to disseminate to patients regardless of their geographical regions, economic or social status.

\subsection{Manageability}

Establishing an inter-organizational network is difficult to achieve due to coordination of multiple organizations that have various organizational cultures. Coordination of the network may be an important obstacle for the tool of collaboration and partnership. As an effective solution to inter-organizational network management, Provan and Millard (2005) claim that integrated and centrally coordinated networks are more likely to be effective than dense, cohesive networks integrated in a decentralized way. Centralization more appropriately facilitates coordination of a network system since decentralized systems are recognized as less able to coordinate and monitor the activities for several organizations.

A centralized network that converges and coordinates multi-party efforts is distinguishable from traditional, hierarchical bureaucratic control due to the various levels of input at the public and community level. However, this approach optimizes a prime feature of bureaucracy because it achieves the level of network effectiveness necessary to produce results through a direct external control mechanism. Therefore, the proposed health literacy policy council coordination role is recommended in order to achieve objectives.

Potentially coercive tools such as social regulation, even in friendly collaboration and partnership situations, are more likely to create opposition from the firms that are required to substantially change their behavior. As a result, they might create resistance to new policy implementation. Subsequently, information regarding the positive consequences of the policy should be given and some incentives could be used to make them more eager for implementation.

\subsection{Legitimacy and Political Feasibility}

Since social regulation can be a coercive tool by nature, owners of private health institutions might be against implementing this new policy and could create pressure on legislators to abandon this policy and/or remove this policy after enactment. Thus, legislators should be given information about the importance of this policy for the future of the health care system including how this regulation will benefit overall public health and well-being.

In summation of the tools of governance determined to be most likely to increase health literacy - cooperation and partnership, social regulation, and direct government, we find an overarching theme of multi-level and interdisciplinary collaboration, communication, and education. We suggest that the maximum benefits towards achieving increased health literacy can occur through the simultaneous use of the selected tools while under the supervision of a health literacy policy council. The proposed council can guide community network development, promote plain language communication, and curriculum development for both the patient and clinical professionals. 


\section{The Program Logic Model Summary}

The program logic model proposed in this paper was established using the guidelines developed by the W.W. Kellogg Foundation (1998). We illustrate this health literacy improvement strategy influenced by such organizations as the U.S. Environmental Protection Agency (2012) and Comprehensive Community Health Models of Michigan (W.W. Kellogg Foundation, 1998). The purpose of the program logic model is to visually represent or chart planned events leading to anticipated problem resolution over time. Basic assumptions in this example rely on the urgency of improved population health that introduces effectiveness and efficiency measures to promote quality of care, the extension of community health through existing strategies of electronic health records and meaningful use, the need for vulnerable populations to achieve improved health status, and the recognition that this complex topic requires mutli-sectoral participation to overcome existing barriers.

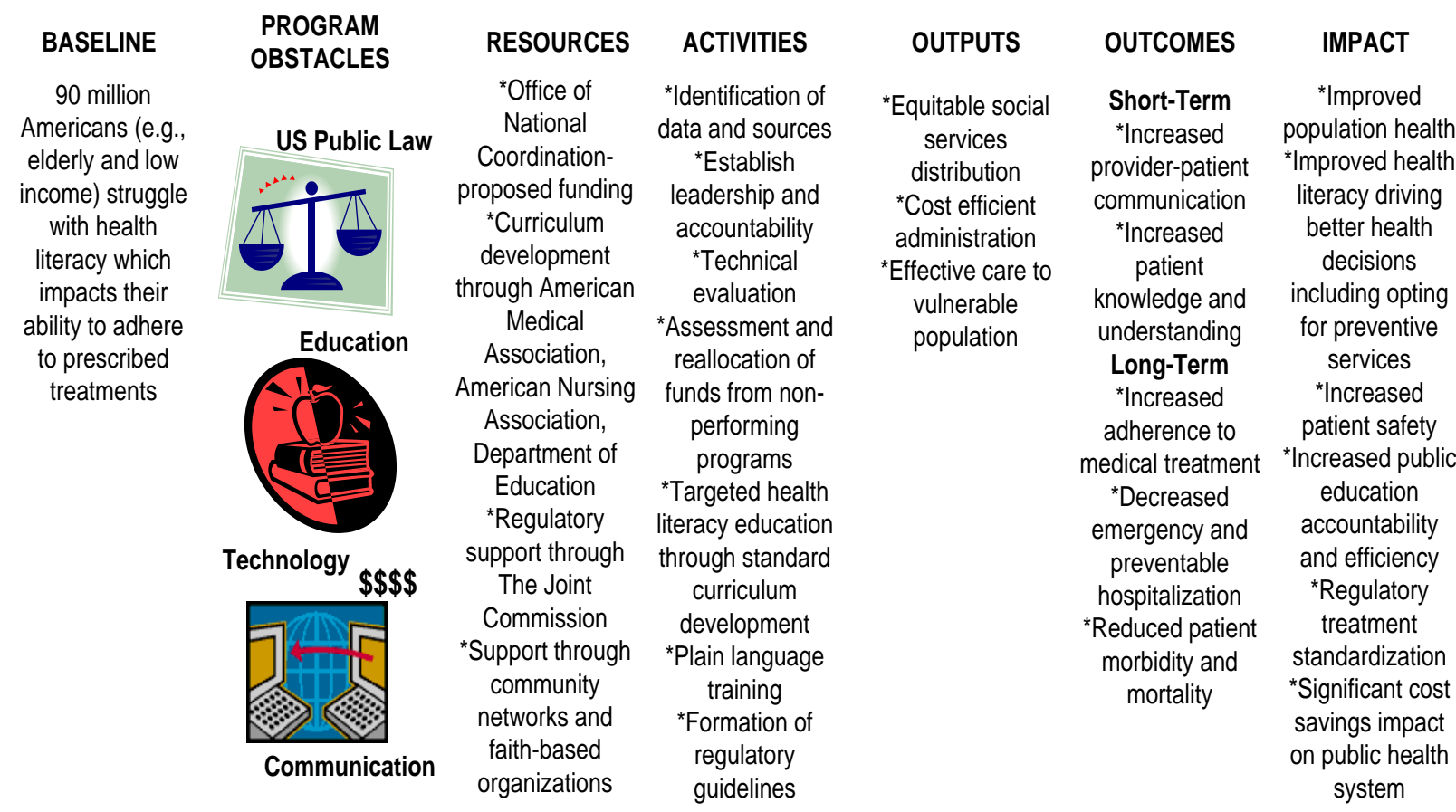

Figure: Health Literacy Program Logic Model

\section{Conclusion}

Health literacy objectives can reduce skyrocketing health costs through improved communication and application of health information by patients and providers. This document has established the multi-faceted and complex issue that indicates the impact of educational, social, and cultural factors that shape population expectations from health care providers and service providers' capability to meet public expectations. A spectrum of governance tools has been presented that promotes public and community cooperation. These tools offer a road map to evaluation of internal structures and policies towards the advancement of health literacy through collaboration and further suggest acceptable outcomes. 
Health care providers should be encouraged to establish a channel in which all health care professionals deal with their patients by using simple and everyday language. An emergent patient-centered approach which aims to make patients understand all viable options available to them in a more concrete way should also be central to the health care system policy.

Actionable items that reduce costs and increase health literacy in the long-term include the use of education to increase health literacy for both the practitioner and the patient. Efforts to corporately increase health literacy will have exponential long-term benefits on quality of life in terms of reduced morbidity and mortality attributed to under or overuse of medication, reduction in emergency room visits, and reduction in long-term costs that were expected to double to $\$ 1$ trillion by 2020 . The reality is that we are already approaching that spending metric a decade ahead of schedule. So, the urgency to eliminate preventable waste attributed to low health literacy through suggested recommendations requires immediate action.

\section{References}

Ad Hoc Committee on Health Literacy (AHCHL) for the Council on Scientific Affairs, American Medical Association. Health Literacy: Report of the Council on Scientific Affairs. The Journal of American Medical Association. 1999; 281, 552-557.

Andrus, M. R., \& Roth, M. T. (2002). Health literacy: A review. Pharmacotherapy, 22 (3), 282-302.

Coulter, A., Entwistle, V., \& Gilbert, D. (1999). Sharing decisions with patients: Is the information good enough? British Medical Journal, 318 (7179), 318-322.

Creed, W. E. D., \& Miles, R. E. (1996). Trust in organizations: A conceptual framework linking organizational forms, managerial philosophies, and the opportunity costs of controls. In R.M. Kramer. \& T.R. Tyler (Eds). Trust in Organizations: Frontiers of Theory and Research (pp. 16-38). Thousands Oaks, CA: Sage.

Davis, T.C., Wolf. M.S., Bass, P.F., Middlebrooks, M., Kennen, E., Baker, D.W., Bennett, C.L., Durazo-Arvizu, R., Bocchini, A., Savory, S., \& Parker, R.M. (2006). Low literacy impairs comprehension of prescription drug warning labels. Journal of General Internal Medicine, 21(8), 847-51.

Dreze, J. \&. Stern, N.H. (1987). The Theory of Cost-Benefit Analysis. In Handbook of Public Economics ( pp. 909-989). Auerbach and M. Feldstein, (Ed). Amsterdam: North-Holland.

Ewert, T., Fuessl, M., Cieza, A., Andersen, C., Chatterji, S., Kostanjsek, N. et al. (2004). Identification of the most common patient problems in patients with chronic conditions using the ICF checklist, Journal of Rehabilitation Medicine, 44, 22-29.

Fiedler, B.A. and Wan, T.T.H. (2010). Disease management organization approach to chronic illness. International Journal of Public Policy, 6 (3/4): 260-77.

Foster-Fishman, P. G., Salem, D. A., Allen, N. A., \& Fahrbach, K. (2001). Facilitating interorganizational collaboration: The contributions of interorganizational alliances. 
American Journal of Community Psychology, 29 (6), 875-905.

Goldsmith, S., \& Eggers, W. D. (2004). Governing by network: The new shape of the public sector. Washington, D.C: Brookings Institution Press.

Institute of Medicine. (2001). Crossing the quality chasm: A new system for the 21 st century. Washington, DC: National Academy Press.

Kemper, D. W., \& Mettler, M. (2002). Information therapy: Prescribed information as a reimbursable medical service. Boise, Idaho: Healthwise, Inc.

Kickbusch, I., Maag, D., \& Saan, H. (2005, October). Enabling healthy choices in modern health societies. Paper presented at the Eighth European Health Forum, Bad Gastein, Austria.

Lane, C., \& Bachmann, R. (1998). Trust within and between organizations. London: Oxford University Press.

Landsbergen, D. \& Wolken, G. (1998). Eliminating Legal and Policy Barriers to Interoperable Government Systems. Paper presented at the Annual research Conference of The Association for Public Policy Analysis and Management, New York.

Literacyworks. (2008). California Health Literacy Initiative. Retrieved March 5, 2014, from http://cahealthliteracy.org/.

Mandell, M., \& Keast, R. (2007). Evaluating network arrangements: Toward revised performance measures. Public Performance \& Management Review, 30 (4), 574-597.

Mattessich, P. W., Murray-Close, M., \& Monsey, B. R. (2001). Collaboration: What makes it work (2nd ed.). St. Paul, MN: Fieldstone Alliance.

Mayeaux, E. J.,Jr, Murphy, P. W., Arnold, C., Davis, T. C., Jackson, R. H., \& Sentell, T. (1996). Improving patient education for patients with low literacy skills. American Family Physician, 53 (1), 205-211.

Moynihan, Donald P. (2005). Leveraging Collaborative Networks in Infrequent Emergency Situations. Madison, WI: IBM Center for The Business of Government, University of Madison-Wisconsin.

National Patient Safety Foundation. (2007). NEW Report Estimates Cost of Low Health Literacy Between \$106 - \$236 Billion Dollars Annually. Retrieved March 5, 2014, from http://www.npsf.org/updates-news-press/press/new-report-estimates-cost-of-low-health-litera cy-between-106-236-billion-dollars-annually/

Newland, C. (2002). Building the futures of local government politics and administration. In The Future of Local Government Administration, Edited by H. George Frederickson and John Nalbandian (pp. 231-263). Washington, D.C: International City/County Management Association.

Nielsen-Bohlman, L., Panzer, A.M., Kindig, D.A. (Eds.). (2008). Health literacy in pharmacy. American Journal of Health System Pharmacy, 65, 974-980. 


\section{Macrothink}

Journal of Public Administration and Governance

ISSN 2161-7104

2014, Vol. 4, No. 1

Nielsen-Bohlman, L., Panzer, A. M., \& Kindig, D. A. (2004). Health literacy: A prescription to end confusion. Washington, D.C: National Academy Press.

Paasche-Orlow, M. K., Taylor, H. A., \& Brancati, F. L. (2003). Readability standards for informed-consent forms as compared with actual readability. New England Journal of Medicine, 348 (8), 721-726.

Parker, R. M., Ratzan, S. C., \& Lurie, N. (2003). Health literacy: A policy challenge for advancing high-quality health care. Health Affairs, 22 (4), 147-153.

Parkhe, A. (1993). Strategic alliance structuring: A game theoretic and transaction cost examination of interfirm cooperation. The Academy of Management Journal, 36 (4), 794-829.

Provan, K.G. \& Milward, H. B. (1995). A preliminary theory of network effectiveness: A comparative study of four community mental health systems. Administrative Science Quarterly, 40 (1), 1-33.

Perrin, B. (1998). How does literacy affect the health of Canadians: A profile paper. Policy Development and Coordination Division, Health Promotion and Programs Branch. Ottawa: Health Canada.

Rawls, J. (1971). A Theory of Justice. The Belknap Press. Rootman, I., \& Ronson, B. (2005). Literacy and health research in Canada: where have we been and where should we go. Canadian Journal of Public Health, 96, 62-67.

Salamon L. M. (ed.) (2002). The Tools of Governance. A Guide to the New Governance. Oxford: Oxford University Press.

Shohet, L. (2002). Health and literacy: Perspectives in 2002. The Centre for Literacy of Quebec. Retrieved March 5, 2014, from http://eric.ed.gov/?id=ED473575.

Shohet, L. (2004). Health and literacy: Perspectives. Literacy and Numeracy Studies, 13 (1), 65-84.

Sihota, S., \& Lennard, L. (2004). Health literacy: Being able to make the most of health. London: National Consumer Council.

Schwartzberg, J.G., VanGeest, J.B., Wang, C.C. (Eds.). (2005). Understanding health literacy: Implications for medicine and public health. Chicago: American Medical Association Press.

Steinemann, A.C., Apgar, W.C., Brown, H.J. (2005). Microeconomics for Public Decisions. Mason, OH: Thomson South-Western.

Taylor-Powell, E., Rossig, B. \& Geran, J. (1998). Evaluating Collaboratives: Reaching the Potential. Madison, WI: University of Wisconsin Extension, Program Development and Evaluation.

Thomas, Craig W. (1997). Public management as interagency cooperation: Testing epistemic community theory at the domestic level. Journal of Public Administration Research and 


\section{Macrothink}

Theory, 7, 221-246.

The Joint Commission (TJC). (2007). "What did the doctor say?" Improving Health Literacy to Protect Patient Safety. Retrieved March 5, 2014, from http://www.jointcommission.org/assets/1/18/improving_health_literacy.pdf.

The Joint Commission (TJC). (2014). National Patient Safety Goals Effective January 1, 2014. Critical Access Hospital Accreditation Program. Retrieved March 5, 2014, from http://www.jointcommission.org/assets/1/6/CAH_NPSG_Chapter_2014.pdf.

Thomson, A. M., Perry, J. L., \& Miller, T. K. (2009). Conceptualizing and measuring collaboration. Journal of Public Administration Research and Theory, 19 (1), 23-56.

Tracz, V. L., Metzger, A., \& Pruchnkicki, M.C. (2008). Health literacy in pharmacy. American Journal of Health System Pharmacy, 65, 974-981.

United States Environmental Protection Agency. (2012). Logic model. Retrieved March 5, 2014, from http://www.epa.gov/reg3esd1/data/logicmodel.htm\#what.

U.S. Department of Health and Human Services. Office of Disease Prevention and Health Promotion. (2010). National Action Plan to Improve Health Literacy. Retrieved March 6, 2014, from http://www.health.gov/communication/HLActionPlan/.

W.W. Kellogg Foundation. 1998. Logic model development guide. Retrieved March 5, 2014 from http://www.wkkf.org/resource-directory/resource/2006/02/wk-kellogg-foundation-logic-mode 1-development-guide.

Wallerstein, N., \& Bernstein, E. (1994). Introduction to community empowerment, participatory education, and health. Health Education Quarterly, 21 (2), 141-148.

Weiss, B.D. (2007). Health Literacy and patient safety: Help patients understand. Manual for Clinicians (2nd ed.). Chicago: AMA and AMA Foundation. 